\title{
Importance of estimation of follicular output rate (FORT) in females assisted by intracytoplasmic sperm injection
}

\author{
Rehana Rehman ${ }^{1 *}$, Rozina Mustafa ${ }^{2}$, Talea Hoor ${ }^{3}$, Rakhshaan Khan $^{4}$, Hina Gul ${ }^{5}$
}

\author{
${ }^{1}$ Department of Biological \& Biomedical Sciences, The Aga Khan University, Karachi -74800, Pakistan \\ ${ }^{2}$ Department of Obstetrics \& Gynecology, Bahria University Medical and Dental College, Karachi, Pakistan \\ ${ }^{3}$ Department of Pharmacology, Bahria University Medical and Dental College, Karachi, Pakistan \\ ${ }^{4}$ MBBS, MPH, Public Health Physician, Islamabad, Pakistan \\ ${ }^{5}$ M.Sc Statistics, Regional Manager, Prontolinks, Karachi, Pakistan
}

Received: 04 December 2014, Revised: 23 December 2014

Accepted: 27 December 2014

\section{*Correspondence:}

Dr. Rehana Rehman,

E-mail: drrehana7@gmail.com

Copyright: (C) the author(s), publisher and licensee Medip Academy. This is an open-access article distributed under the terms of the Creative Commons Attribution Non-Commercial License, which permits unrestricted non-commercial use, distribution, and reproduction in any medium, provided the original work is properly cited.

\begin{abstract}
Background: We aimed to estimate pregnancy outcome after ICSI in terms of oocyte parameters, embryo quality, endometrial thickness, hormone and cytokine levels in women stratified on the basis of follicular output rate (FORT). Methods: Quasi experimental design was carried out after approval from "Ethical review board of Islamabad clinic serving infertile couples" from July 2010 to August 2013. One thousand and fifty females were selected with the criteria of age between 21-40 years, infertility of more than 2 years, body mass index of $18-35 \mathrm{~kg} / \mathrm{m}^{2}$, menstrual cycle of $25 \pm 7$ days, both ovaries present with normal uterine cavity, serum FSH levels less than $8 \mathrm{IU} / \mathrm{ml}$ and normal thyroid-stimulating hormone levels. Females on short agonist or antagonist protocol with diagnosis of polycystic ovarian syndrome, fibroids or in their male partner sperms retrieved by testicular biopsy were excluded from the study. Down regulation of ovaries was followed by controlled ovarian stimulation, Ovulation Induction (OI), oocyte pick up, in vitro fertilization, Embryo Transfer (ET) and confirmation of pregnancy was done by serum beta hCG of more than $25 \mathrm{mIU} / \mathrm{ml}$ and cardiac activity on trans vaginal scan. Enzyme linked immuno sorbent assay was used for peak and mid luteal estradiol (E2), progesterone (P) and interleukin I- $\beta$ estimation on OI and ET days respectively. FORT (ratio of preovulatory follicle count to antral follicle count $\times 100$ on OI day) stratified females into low under the $33^{\text {rd }}$ percentile, medium between the $33^{\text {rd }}$ and the $67^{\text {th }}$ percentile and high above the $67^{\text {th }}$ percentile. Characteristics of groups were compared by one way analysis of variance.

Results: Females 276 (33\%), 288 (34\%) and $282(33 \%)$ comprised of low, medium and high FORT groups respectively. The number of retrieved, mature and fertilized oocytes, cleaved embryos, endometrial thickness and number of gestational sacs in the high FORT group was significantly high $(\mathrm{P}<0.001)$. High peak and midluteal E2 (P $=0.0025,0.0001)$, low $\mathrm{P}(\mathrm{P}=0.0001)$ and high peak interleukin-1 $\beta(\mathrm{P}=0.0001)$ was observed in high FORT in comparison with medium FORT with resultant greater number of clinical pregnancies 183 (65\%).

Conclusions: The FORT in non PCOS patients may reflect good reproductive outcome after ICSI with maximum clinical pregnancies in high FORT group.
\end{abstract}

Keywords: Intracytoplasmic sperm injection, Follicular output rate (FORT), Preovulatory follicle count, Antral follicle count 


\section{INTRODUCTION}

The health impact of infertility has resulted in aggravation of medical, social, psychological and economic burdens in developing countries. ${ }^{1}$ Stress of infertility disturbs wellness of a couple in general and women in particular, resulting in emotional instability, distress and anxiety that may end up in depression. ${ }^{2}$ The resolution to the issue is provided by "Assisted reproductive clinics" where a number of treatment procedures are offered for the above. Intra Cytoplasmic Sperm Injection (ICSI) is one of the advanced techniques conceded after down regulation of ovaries, Controlled Ovarian Stimulation (COS), Oocyte Pick Up (OPU) and micro injection of spermatozoa followed by Embryo Transfer (ET). ${ }^{3,4}$

COS in ICSI procedures employs recruitment of multiple follicles that grow and finally develop into mature follicles. Stimulation is achieved by administration of recombinant forms of exogenous gonadotrophin which increases follicular recruitment, maturation of follicles and multiple eggs production. ${ }^{5}$ The attempt increases the number of oocytes for possibility of fertilization and cleavage of embryos available for transfer improving success rates. ${ }^{6,7}$ The number of oocytes retrieved can be predicted by several factors: especially female age, Antral Follicle Count (AFC), basal Follicle Stimulating Hormone (FSH) and Body Mass Index (BMI).

AFC represents number of remaining primordial pool in women and corresponds to the number of oocytes retrieved, however it does not influence oocyte/embryo quality and in turn outcome of ICSI. ${ }^{8-10}$

The number of preovulatory follicles obtained at the end of COS at the same time is not a reliable reflection of antral follicle sensitivity to FSH, since it is subject to a number of small antral follicles available before treatment. ${ }^{11}$ In this context, follicular output rate (FORT) has proved itself to be a qualitative reflector of ovarian follicular competence in terms of percentage of antral follicles that effectively respond to FSH after COS in ICSI patients. ${ }^{11}$

The need for estimation of FORT is hypothesized from the fact that follicle and oocyte dysfunction limit the sensitivity of antral follicles to exogenous FSH with the role of FORT as an important predictor of antral follicle responsiveness. This is especially useful to ignore $40 \%$ atretic follicles that might give false results to the expected stimulation. ${ }^{12}$

We wanted to predict accuracy of FORT to assess response of follicles to $\mathrm{COS}$ and reproductive outcome after ICSI. The present study aimed to demarcate FORT groups and compare them in terms of oocyte parameters, embryo quality, endometrial thickness together with hormones and cytokines in preovulatory and midluteal phase of women undergoing ICSI.

\section{METHODS}

Quasi experimental design study in which convenience sampling of 1050 consented couples was performed after approval from "Ethical review board of Islamabad clinic serving infertile couples" from June 2010 till August 2013. Females within the age range of $21-40$ years who fulfilled the following inclusion criteria; primary infertility for more than 2 years, menstrual cycle of $25 \pm$ 7 days, BMI of $18-35 \mathrm{~kg} / \mathrm{m}^{2}$, presence of both ovaries with normal uterine cavity, serum FSH levels less than 8 $\mathrm{IU} / \mathrm{ml}$ and normal thyroid-stimulating hormone levels. Females on short agonist or antagonist protocol, diagnosed as polycystic ovarian syndrome (PCOS) or fibroids, and sperm retrieval by testicular biopsy were excluded from the study.

\section{Ethics statement}

The study is being conducted in compliance with the principles of the Declaration of Helsinki with standards that protect the rights of participants including policies on informed consent. The study was carried out at a private hospital (ICSI) in Islamabad. Dr. Nasim Ashraf was the managing director/chairperson of the research ethics committee. Other members included Dr. Anjum A. Siddiq and Dr. Shaheen Javed. After the institutional approval of the study all the participants read and signed the informed consent.

\section{Treatment protocol}

Written consent, base line investigations, hormone profile and $\mathrm{AFC}$ were performed when the patients were booked for ICSI. Down regulation of ovaries by mid luteal suppression of hypothalamo-pituitary-ovarian axis was made possible with daily injection of decapeptyl (gonadotrophin hormone agonist; GnRha) $0.1 \mathrm{mg}$ (Ferring, Copenhagen NV) from D-21 of the preceding cycle. COS was acquired with rFSH (Injection Puregon $\mathrm{S} / \mathrm{C}$ ) from second day of cycle with follicular tracking from fifth day by sequence of trans vaginal scan (TVS, 7.5 MHz probe Aloka 500, Tokyo Japan) till maximum follicles acquired a size of $20 \mathrm{~mm} 13 \pm 2$ days.

AFC was measured on day 2 or 3 of cycle (number of all follicles measuring 3-8 $\mathrm{mm}$ in diameter.) before initiation of stimulation. On Ovulation Induction day (OI), all follicles $16-22 \mathrm{~mm}$ in diameter were calculated in both ovaries to mark Peak Follicular Count (PFC). The FORT was calculated by the ratio between PFC on dhCG $\times$ 100/AFC at baseline. ${ }^{11}$ To interpret the possible relationship between follicle responsiveness to COS and ICSI outcome, study population was stratified into three distinct FORT groups on the basis of tertile values; low, medium and high. FORT values were under the $33^{\text {rd }}$ percentile $(<47 \%$, in the low FORT group) between the $33^{\text {rd }}$ and the $67^{\text {th }}$ percentile $(42-58 \%$, in the medium FORT group), or above the $67^{\text {th }}$ percentile ( $>58 \%$, in the high FORT group). The endometrial thickness was also 
measured on the same day and blood samples taken for estimation of estradiol (E2), progesterone (P) and interleukin-I $\beta$ (IL-I $\beta$ ). OPU was done 36 hours after OI by intra muscular injection of hCG (Pregnyl 10000 IU) by vaginal ultrasound probe and double lumen oocyte aspiration needle. Progesterone vaginal pessaries (Cyclogest $400 \mathrm{mg}$ ) were given once a day from the day of OPU. The micromanipulators (Research Instrument Inc.UK) were used with $30^{\circ}$ bend microinjection and holding pipettes (Hunter Scientific Essex, UK). The oocyte was held in place with a holding pipette and micro injection of spermatozoa was performed at right angle to polar body. Micro injected eggs were then rinsed in several micro drops of culture medium G1 Plus with $10 \%$ human serum albumin and then incubated for 16-18 hours at $37^{\circ} \mathrm{C}, 6 \% \mathrm{CO}_{2}$ and $5 \% \mathrm{O}_{2}$.

Fertilization was assessed 16-20 hours after ICSI by presence of two pronuclei. The fertilized oocytes were then cultured for $24-30$ hours at $37^{\circ} \mathrm{C}$ in fresh $\mathrm{CO}_{2}$ equilibrated G1 Plus medium. Cleavage of embryos was confirmed after another 24-hour. Embryos were evaluated on alternate days. All embryos were graded (Grades 1-5 from best to worst) on day three for the assessment of embryo quality from cleavage to differentiation. ${ }^{13}$ Grade 1: embryos with evenly sized blastomeres and no fragmentation, grade 2: embryos with uneven or irregularly shaped blastomere/fragmentation (no more than 10\%), grade 3, 4 and 5 embryos with fragmentation $\geq 25 \% \quad 50 \%$ and $75 \%$ respectively and unequal blastomeres.

ET of blastocysts were performed seven days after OI by Sims-Wallace embryo replacement catheter guided through ultrasound. Samples for mid luteal estimation of E2, P and IL-I $\beta$ were taken on the day of transfer. Serum Beta hCG was assessed 10 days after ET which categorized females into non pregnant if levels were 5-25 $\mathrm{mIU} / \mathrm{ml}$, and clinical pregnancy with beta hCG $>25 \mathrm{~m}$ $\mathrm{IU} / \mathrm{ml}$ and appearance of gestational sac with cardiac activity on TVS (4 weeks after ET).

\section{Statistical analysis}

Data was analyzed by SPSS (version 15; SPSS Inc., Chicago, IL, USA). The qualitative variables were represented by frequencies and percentages like (age group), mean $\pm \mathrm{SD}$ for continuous/quantitative variables. Results of FORT groups were compared by analysis of variance (ANOVA) with significance at $\mathrm{P}$ value $<0.05$. Reproductive outcomes and the associated rates (in percentages) were described by standard definitions as follows. Oocyte recovery rate was "number of oocytes retrieved with respect to number of counted follicles by TVS $\times 100 .{ }^{14}$ Fertilization Rate (FR) was percentage of micro injected oocytes transforming into two pronuclei formation. ${ }^{15}$ The Implantation Rate (IR) was percentage of gestational sacs visualized on TVS per number of embryos transferred. ${ }^{16}$ A Pregnancy Rate (PR) was derived by presence of an intrauterine gestational sac with cardiac activity observed on TVS per number of patients at the beginning of the cycle. ${ }^{14}$

\section{RESULTS}

Of the 1050 recruited patients, ET was performed in 846 patients. The patient characteristics, ovarian stimulation data and outcomes in clinically pregnant (303 cycles) and non-pregnant (543 cycles) females is described in Table 1. The patient characteristics, ovarian stimulation data in Table 1 shows difference in non-pregnant and pregnant females $(0.49 \pm 0.12$ versus $0.64 \pm 8.97, \mathrm{P}<0.001)$. Out of 846 females, $276(33 \%), 288(34 \%)$ and $282(33 \%)$ were in the low, medium and high FORT groups respectively. The total number of couples who had clinical pregnancy (as documented by beta hCG more than $25 \mathrm{mIU} / \mathrm{ml}$ along with the presence of gestational sac and cardiac activity) were 303/846 with an overall pregnancy rate of $36 \%$ per embryo transfer. Clinical pregnancy was acquired by $24(8.7 \%), 96(33 \%)$ and 183 $(65 \%)$ females in low, medium and high FORT groups respectively (Figure 1).

The cycle characteristics identified the cause of infertility at the time of booking of patients. The age of females was grouped as follows: up to 25 years, 26-30 years, 31-35 years and above 35 years. Out of total 846 females, 252 (29.8\%), $255(30.1 \%)$ and $249(29.4 \%)$ belonged to $26-$ $30,31-35$ and above 35 years age groups respectively. The age however presented no relation to conception in either FORT group as the mean age at the time of marriage was the same across all groups. The mean duration of infertility was 7.11 years that showed no relation to the instance of becoming pregnant in either FORT groups. The Body Mass Index (BMI) in the study group ranged between $23.55 \pm 3.86 \mathrm{~kg} / \mathrm{m}^{2}$ with 381 $(45 \%)$ women in the obese category (BMI $>26 \mathrm{~kg} / \mathrm{m}^{2}$ ) and $63(7.4 \%)$ in the underweight category (BMI $<18$ $\mathrm{kg} / \mathrm{m}^{2}$ ) yet this showed no relationship with the cycle characteristics in any FORT group. BMI in high FORT was less as compared to other groups but was not significant as shown in Table 2. Almost one out of four of all women (23.4\%) showed some sort of addiction with proportionally a greater number in the medium FORT groups that had no noteworthy relation to conception. Ovarian volume measured by ultrasound was the same in all groups while the AFC was higher in the low FORT group $(\mathrm{P}=0.004)$.

The stratification of patients on the basis of cycle characteristics in FORT groups is shown in Table 2, mean FORT was $0.54 \pm 13.60$. FORT was correlated with $\operatorname{AFC}(\mathrm{r}=-0.560, \mathrm{P}<0.0001)$, PFC $(\mathrm{r}=0.655, \mathrm{P}<0.001)$, FSH $(r=-0.259, \mathrm{P}<0.001)$, gonadotrophins used $(\mathrm{r}=-$ $0.201, \mathrm{P}<0.001)$, number of oocytes $(\mathrm{r}=0.671, \mathrm{P}$ $<0.001)$, fertilized oocytes $(\mathrm{r}=0.541, \mathrm{P}<0.001)$, and cleaved embryos $r=-0.511 \mathrm{P}<0.001)$.

The response to ovarian stimulation in various FORT groups is shown in Table 3. 
Table 1: Characteristics, ovarian stimulation data and ICSI outcomes of non PCOS patients.

\begin{tabular}{|c|c|c|c|}
\hline & $\begin{array}{l}\text { No conception } \\
\mathbf{N}=\mathbf{5 4 3}\end{array}$ & $\begin{array}{l}\text { Conception = } \\
303\end{array}$ & $\begin{array}{l}P \\
\text { value }\end{array}$ \\
\hline $\begin{array}{l}\text { Female age } \\
\text { (years) }\end{array}$ & $32.07 \pm 4.63$ & $32.17 \pm 4.71$ & NS \\
\hline $\begin{array}{l}\text { Duration of } \\
\text { infertility } \\
\text { (years) }\end{array}$ & $6.91 \pm 3.79$ & $7.45 \pm 4.00$ & NS \\
\hline $\begin{array}{l}\text { Body mass } \\
\text { index (BMI) }\end{array}$ & $24.62 \pm 3.67$ & $23.56 \pm 3.63$ & 0.020 \\
\hline $\begin{array}{l}\text { Basal } \\
\text { progesterone } \\
(\mathrm{ng} / \mathrm{ml})\end{array}$ & $9.41 \pm 3.98$ & $17.01 \pm 8.97$ & 0.000 \\
\hline $\begin{array}{l}\text { Follicle } \\
\text { stimulating } \\
\text { hormone } \\
\text { (IU/L) }\end{array}$ & $6.91 \pm 1.19$ & $6.27 \pm 0.69$ & 0.000 \\
\hline $\begin{array}{l}\text { Estradiol } \\
\text { before } \\
\text { treatment } \\
(\mathrm{pg} / \mathrm{ml})\end{array}$ & $170.44 \pm 108.38$ & $294.12 \pm 169.40$ & 0.000 \\
\hline $\begin{array}{l}\text { Antral follicle } \\
\text { count (AFC) }\end{array}$ & $15.54 \pm 2.52$ & $13.06 \pm 2.55$ & 0.000 \\
\hline $\begin{array}{l}\text { Total No. of } \\
\text { gonadotropins } \\
\text { (IU) }\end{array}$ & $59 \pm 10.17$ & $53.99 \pm 5.72$ & 0.000 \\
\hline $\begin{array}{l}\text { Duration of } \\
\text { gonadotropins } \\
\text { (days) }\end{array}$ & $14.43 \pm 0.96$ & $14.15 \pm 0.95$ & 0.021 \\
\hline $\begin{array}{l}\text { Preovulatory } \\
\text { follicle count }\end{array}$ & $7.52 \pm 1.89$ & $8.30 \pm 1.70$ & 0.001 \\
\hline $\begin{array}{l}\text { Follicular } \\
\text { output rate }\end{array}$ & $49.44 \pm 12.91$ & $64.08 \pm 8.97$ & 0.000 \\
\hline $\begin{array}{l}\text { No. of oocytes } \\
\text { / patient }\end{array}$ & $7.40 \pm 1.68$ & $8.20 \pm 1.52$ & 0.000 \\
\hline $\begin{array}{l}\text { Number of } \\
\text { oocytes } \\
\text { metaphase II }\end{array}$ & $6.62 \pm 2.03$ & $8.03 \pm 1.44$ & 0.000 \\
\hline $\begin{array}{l}\text { Number of } \\
\text { oocytes } \\
\text { fertilized }\end{array}$ & $5.55 \pm 1.64$ & $6.65 \pm 1.07$ & 0.000 \\
\hline $\begin{array}{l}\text { Fertilization } \\
\text { rate }\end{array}$ & $75 \pm 17.28$ & $81.71 \pm 6.79$ & 0.000 \\
\hline $\begin{array}{l}\text { Number of } \\
\text { transferred } \\
\text { embryos }\end{array}$ & $1.58 \pm 0.58$ & $1.70 \pm 0.57$ & 0.091 \\
\hline $\begin{array}{l}\text { Number of } \\
\text { gestational } \\
\text { sacs }\end{array}$ & $0.01 \pm 0.12$ & $1.35 \pm 0.48$ & 0.000 \\
\hline $\begin{array}{l}\text { Endometrial } \\
\text { thickness } \\
(\mathrm{mm})\end{array}$ & $7 \pm 2.95$ & $11.45 \pm 2.03$ & 0.000 \\
\hline $\begin{array}{l}\text { Number of } \\
\text { cleaved } \\
\text { embryos }\end{array}$ & $5.46 \pm 1.58$ & $6.56 \pm 1.04$ & 0.000 \\
\hline
\end{tabular}

Values expressed as Mean \pm SD

Groups compared by $\mathrm{T}$ test

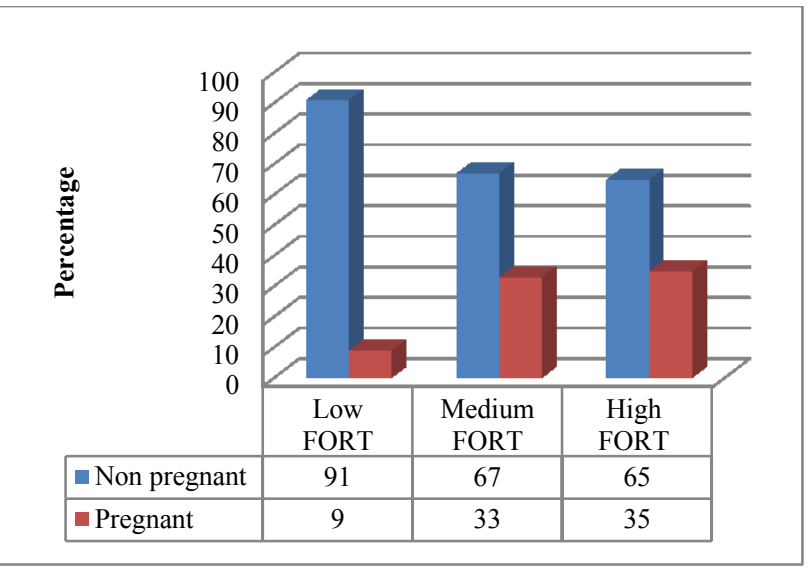

Figure 1: Comparison of pregnancy outcome on the basis of FORT.

- $\quad$ FORT $=$ pre follicular count/antral follicle count $\times 100$

- Pre follicular count; measurement of follicle on the day of hCG

- Antral follicle count: $(3-8 \mathrm{~mm})$ at baseline (just before the start of FSH treatment).

- $\quad$ Low FORT under the $33^{\text {rd }}$ percentile

- Medium FORT between the $33^{\text {rd }}$ and the $67^{\text {th }}$ percentile

- $\quad$ High FORT above the $67^{\text {th }}$ percentile

- Results of high FORT significant with medium and low FORT

Comparison of PFC, oocyte parameters and embryo quality was highest in high FORT group $(\mathrm{P}>0.0001)$ with significantly higher number of PFC, retrieved, mature and fertilized oocytes and top quality cleaved embryos. No significant relationship was observed in number of gonadotrophins (Puregons) used per patient per day and the total amount used by each patient. The endometrial thickness varied between $8.58 \pm 3.41 \mathrm{~mm}$ and was significantly more $(\mathrm{P}>0.0001)$ in medium FORT group. The formation of blastocysts was also significantly on the higher side in medium group whereas number of gestational sacs was high in high FORT group (Table 3).

Table 4 shows the comparison of base line hormones, a low FSH $(\mathrm{P}=0.04)$ and a high basal pretreatment E2 level $(\mathrm{P}=0.0001)$ in females of high FORT group. The peak level hormones show higher E2 $(\mathrm{P}=0.0025)$, low $\mathrm{P}$ $(\mathrm{P}=0.0001)$ and higher IL-1 $\beta(\mathrm{P}=0.0001)$ whereas the mid luteal hormones showed higher E2 $(\mathrm{P}=0.0001)$ and significantly lower $\mathrm{P}$ levels $(\mathrm{P}=0.0001)$. E/P ratio on OI day was significantly high $(\mathrm{P}=0.0001)$ in the high FORT group.

Comparing the reproductive outcome rates among the FORT groups (Table 5), the oocyte maturity rate and the fertilization rate had no striking notable difference between the groups but the implantation rate was significantly higher in high FORT group resulting in 183 (65\%) pregnancies as compared to medium FORT group that result in $96(33 \%)$ pregnancies $(\mathrm{P}>0.0004)$. 
Table 2: Comparison of cycle characteristics in FORT groups.

\begin{tabular}{|c|c|c|c|}
\hline & $\begin{array}{l}\text { Low FORT }{ }^{\Omega} \\
(<0.47 ; n=276)\end{array}$ & $\begin{array}{l}\text { Medium FORT } \\
(0.47-0.63 ; n=288)\end{array}$ & $\begin{array}{l}\text { High FORT } \\
(>0.63 ; n=282)\end{array}$ \\
\hline Variables & Mean \pm SD & Mean \pm SD & Mean \pm SD \\
\hline Female age (years) & $31.42 \pm 4.83$ & $32.22 \pm 4.43$ & $32.66 \pm 4.65$ \\
\hline Age at marriage & $25.55 \pm 4.544$ & $24.77 \pm 3.25$ & $25.67 \pm 4.75$ \\
\hline BMI $\left(\mathrm{kg} / \mathrm{m}^{2}\right)$ & $24.44 \pm 3.76$ & $24.55 \pm 3.50$ & $23.73 \pm 3.76$ \\
\hline Duration of infertility (years) & $6.87 \pm 3.95$ & $7.45 \pm 3.84$ & $6.98 \pm 3.82$ \\
\hline Systolic blood pressure (mm Hg) & $120.56 \pm 4.94$ & $121.11 \pm 5.28$ & $120.11 \pm 4.81$ \\
\hline Diastolic blood pressure (mm Hg) & $76.33 \pm 4.14$ & $75.31 \pm 3.77$ & $75.74 \pm 3.91$ \\
\hline Antral follicular count & $16.71 \pm 1.36$ & $14.25 \pm 3.05$ & $13.06 \pm 2.32 * * \circ \circ$ \\
\hline Ovarian volume by ultrasound $\mathrm{mm}^{3}$ & $11.54 \pm 3.53$ & $11.70 \pm 3.29$ & $11.40 \pm 2.84$ \\
\hline
\end{tabular}

$\Omega$ Low FORT group values were under the $33^{\text {rd }}$ percentile

-) Medium FORT values between the $33^{\text {rd }}$ and $67^{\text {th }}$ percentile

$\neq$ High FORT values above the $67^{\text {th }}$ percentile

*Results of high FORT significant with low FORT; $p$ value $<0.05$

**Results of high FORT significant with low FORT; $p$ value $<0.01$

${ }^{\circ}$ Results of high FORT significant with high FORT; $p$ value $<0.05$

${ }^{\circ}$ Results of high FORT significant with high FORT; $p$ value $<0.01$

Table 3: Comparison of ovarian stimulation data in FORT groups.

\begin{tabular}{|c|c|c|c|}
\hline & $\begin{array}{l}\text { Low FORT } \\
(<0.47 ; n=276)\end{array}$ & $\begin{array}{l}\text { Medium FORT } \\
(0.47-0.63 ; n=288)\end{array}$ & $\begin{array}{l}\text { High FORT } \\
(>0.63 ; n=282)\end{array}$ \\
\hline Number of puregons used in one day & $4.20 \pm 0.82$ & $3.96 \pm 0.61$ & $3.84 \pm 0.50$ \\
\hline Total number of gonadotropins (IU) & $60.45 \pm 11.70$ & $56.62 \pm 7.93$ & $54.62 \pm 6.10$ \\
\hline Preovulatory follicle count & $6.34 \pm 0.83$ & $7.96 \pm 1.69$ & $9.06 \pm 1.78 * * \circ \circ$ \\
\hline No of oocytes/ patient & $6.33 . \pm 082$ & $7.84 \pm 1.54$ & $8.86 \pm 1.45 * * \circ \circ$ \\
\hline No of oocytes Metaphase II & $5.57 \pm 1.52$ & $7.27 \pm 1.91$ & $8.33 \pm 1.49 * * \circ \circ$ \\
\hline No of oocytes fertilized & $4.88 \pm 1.25$ & $6.06 \pm 1.54$ & $6.87 \pm 1.16^{* * \circ \circ}$ \\
\hline Fertilization rate & $77.10 \pm 16.62$ & $77.64 \pm 14.61$ & $78.66 \pm 12.89$ \\
\hline Endometrial thickness & $5.17 \pm 2.65$ & $10.06 \pm 2.97$ & $8.46 \pm 3.38 * * \circ \circ$ \\
\hline Number of cleaved embryos & $4.88 \pm 1.25$ & $6.06 \pm 1.54$ & $6.67 \pm 1.11 * * \circ \circ$ \\
\hline Grade_1 & $0.33 \pm 0.49$ & $3.12 \pm 1.61$ & $1.91 \pm 1.48 * * \circ \circ$ \\
\hline Grade_2 & $1.91 \pm 0.28$ & $1.91 \pm 0.28$ & $1.91 \pm 0.28$ \\
\hline Grade_3 & $1.04 \pm 0.35$ & $1.66 \pm 0.49$ & $1.26 \pm 0.50$ \\
\hline Blastocysts formed & $1.66 \pm 0.49$ & $2.29 \pm 0.61$ & $2.08 \pm 0.52 * * \circ \circ$ \\
\hline No of transferred embryos & $1.63 \pm 0.54$ & $1.59 \pm 0.59$ & $1.64 \pm 0.61$ \\
\hline Number of gestational sacs & $0.12 \pm 0.410$ & $0.49 \pm 0.71$ & $0.88 \pm 0.74 * * \circ \circ$ \\
\hline
\end{tabular}

*Results of high FORT significant with low FORT; $p$ value $<0.05$

$* *$ Results of high FORT significant with low FORT; $p$ value $<0.01$

${ }^{\circ}$ Results of high FORT significant with high FORT; $p$ value $<0.05$

${ }^{\circ}$ Results of high FORT significant with high FORT; $p$ value $<0.01$

Table 4: Hormone profile of patients in FORT groups

\begin{tabular}{|llll|} 
& $\begin{array}{l}\text { Low FORT } \\
(<0.47 ; n=276)\end{array}$ & $\begin{array}{l}\text { Medium FORT } \\
(0.47-0.63 ; n=288)\end{array}$ & $\begin{array}{l}\text { High FORT } \\
(>0.63 ; n=282)\end{array}$ \\
\hline $\mathrm{LH}^{\mathcal{O}} \mathrm{IU} / \mathrm{L}$ & $4.66 \pm 1.23$ & $5.27 \pm 1.44$ & $5.65 \pm 1.43^{* * \circ \circ}$ \\
\hline $\mathrm{FSH}^{\mu} \mathrm{IU} / \mathrm{L}$ & $7.04 \pm 1.31$ & $6.65 \pm 0.99$ & $6.36 \pm 0.07^{*}$ \\
\hline Estradiol pg/ml & $156.25 \pm 77.02$ & $209.32 \pm 143.59$ & $277.73 \pm 173.03 * * \circ \circ$ \\
\hline Prolactin $\mathrm{ug} / \mathrm{ml}$ & $21.19 \pm 5.56$ & $22.99 \pm 5.14$ & $22.85 \pm 6.28^{\circ *}$ \\
\hline Progesterone $\mathrm{ng} / \mathrm{ml}$ & $8.797 \pm 2.2954$ & $12.001 \pm 7.3419$ & $13.615 \pm 7.2051$ \\
\hline Estradiol $\mathrm{pg} / \mathrm{ml}$ & $2201.91 \pm 302.45$ & $2347.33 \pm 281.13$ & $2416.55 \pm 290.4^{* * \circ \circ}$ \\
\hline
\end{tabular}




\begin{tabular}{|llll|}
\hline Progesterone $\mathrm{ng} / \mathrm{ml}$ & $1.75 \pm 0.72$ & $1.55 \pm 0.71$ & $1.11 \pm 0.64^{* *}$ \\
\hline Interleukin $-\mathrm{I} \beta \mathrm{pg} / \mathrm{ml}$ & $65.69 \pm 52$ & $118.99 \pm 61.57$ & $145.47 \pm 51.54^{* * \circ \circ}$ \\
\hline Estradiol $\mathrm{pg} / \mathrm{ml}$ & $897.15 \pm 114.87$ & $966.697 \pm 152.12$ & $962.25 \pm 158.29^{* * \circ}$ \\
\hline Progesterone $\mathrm{ng} / \mathrm{ml}$ & $183.59 \pm 36.08$ & $147.80 \pm 52.82$ & $115.84 \pm 49.71^{* * \circ \circ}$ \\
\hline Interleukin $-\mathrm{I} \beta \mathrm{pg} / \mathrm{ml}$ & $58.59 \pm 23.08$ & $54.61 \pm 22.03$ & $43.96 \pm 15.13^{* *}$ \\
\hline E/P $\mathrm{P}^{\pi}$ ratio on OI day & $1.56 \pm 0.97$ & $2.08 \pm 1.60$ & $3.20 \pm 2.14^{* * \circ \circ}$ \\
\hline
\end{tabular}

$\mathrm{LH}^{\odot}$ Luteinizing hormone

$\mathrm{FSH}^{\mu}$ Follicle Stimulating hormone, E/ $\mathrm{P}^{\pi}$ Estradiol Progesterone ratio

*Results of high FORT significant with low FORT; P value $<0.05$

**Results of high FORT significant with low FORT; P value $<0.01$

${ }^{\circ}$ Results of high FORT significant with high FORT; P value $<0.05$

${ }^{\circ}$ Results of high FORT significant with high FORT; P value $<0.01$

Table 5: Comparison of reproductive rates.

\begin{tabular}{|llll|} 
& $\begin{array}{l}\text { Low FORT } \\
(<0.47 ; n=276)\end{array}$ & $\begin{array}{l}\text { Medium FORT } \\
(\mathbf{0 . 4 7 - 0 . 6 3} ; n=288)\end{array}$ & $\begin{array}{l}\text { High FORT } \\
(>0.63 ; n=282)\end{array}$ \\
\hline Cleavage rate & $77.1 \pm 16.62$ & $76.86 \pm 14.84$ & $76.57 \pm 13.87$ \\
\hline Oocyte maturity rate & $91.06 \pm 21.31$ & $92.8 \pm 16.88$ & $94.95 \pm 14.13$ \\
\hline Fertilization rate & $77.1 \pm 16.62$ & $77.64 \pm 14.61$ & $78.67 \pm 12.89$ \\
\hline Implantation. rate & $7.61 \pm 25.61$ & $30.9 \pm 43.86$ & $54.08 \pm 43.36^{* * \circ 0}$ \\
\hline
\end{tabular}

- Values expressed as Mean $\pm \mathrm{SD}$

- Groups compared by one way of analysis of variance

- Oocyte maturity rate $(\%)=$ Total number of metaphase II oocytes / Total number of oocytes retrieved $\times 100$

- Fertilization rate $(\%)=$ Total number of 2 pronuclei $/$ Total number of oocytes microinjected $\times 100$

- Implantation rate $(\%)=$ Total number of gestational sacs/ Total number of embryos transferred $\times 100$

*Results of high FORT significant with low FORT; P value $<0.05$

$* *$ Results of high FORT significant with low FORT; P value $<0.01$

${ }^{\circ}$ Results of high FORT significant with high FORT; P value $<0.05$

${ }^{\circ}$ Results of high FORT significant with high FORT; P value $<0.01$

\section{DISCUSSION}

Human ovary is gifted with a fixed number of primordial follicles which steadily decline throughout life due to recruitment towards ovulation. The pattern decline is not symmetrical and maximum follicles have already been lost when females approach to infertility clinic. ${ }^{17}$ There is no single marker that can predict ovarian response, oocyte competence, endometrial receptivity and embryo quality. However appropriate response of antral follicles to FSH and a high quality of oocytes is associated with favorable outcome after ICSI. ${ }^{10,17,18}$ The weak predictability of absolute $\mathrm{AFC}^{9}$ led to consideration of FORT as an innovative measure to assess follicle response to exogenous $\mathrm{FSH}^{18}$

Results suggest that the response of female reproductive system during COS is different from the one during normal cycles. ${ }^{19}$ During this period, fluctuations in levels of LH and FSH from anterior pituitary and E2 from ovaries are primarily involved to elicit changes in structure, maturity and release of eggs. This behavior can be predicted by a number of Ovarian Reserve Tests (ORT); of these, basal FSH in this regards has been established as a reliable ORT and negative predictor of number of oocytes in pituitary suppression cycle. A high FSH is associated with ovarian aging, poor ovarian response, decline in oocyte quality, reduction in pregnancy rates and increase in miscarriage rates. ${ }^{20}$ Metaanalysis has however determined that basal FSH cannot be used to predict ICSI outcome because of inter cyclic variability. The results of our study establish that females who had a FORT of $>63 \%$ had low FSH, maximum number of oocytes and highest number of clinical pregnancies similar to another study by Jurema et al. ${ }^{21}$ High FORT group had high basal E2, which is a sensitive predictor of ovarian response and pregnancy rate as also shown in another study. ${ }^{22}$ The basal serum LH does not predict IVF/ICSI clinical pregnancy in routine fertility and endocrinological conditions. ${ }^{23}$

In this study it is observed that effect of ovarian aging on FORT is negligible as compared to PFC, basal E2 and FSH levels and antral follicles continue to respond to FSH irrespective of ovarian aging which is supported by other studies. $^{11,24}$ 
The present study reflected that high peak E2 (at the time of OI) is associated with greater number of oocytes maturity, retrieval, fertilization, cleavage and the number of top quality embryos which enhance chances of clinical pregnancy as observed in other studies ${ }^{14,25}$ The suggested high peak E2 for improvement of oocyte and embryo quality was observed in high FORT group of our study, similar results were shown in another study. ${ }^{26,27}$ The increased E2 produced by growing follicles in the window of implantation, increases endometrial receptivity by apposition, attachment and apposition for the encroaching blastocyst. ${ }^{27,28}$ In this study a high midluteal E2 levels in high FORT was associated with better pregnancy outcome after ICSI as other studies also have documented improvement of results with a high mid luteal E2. ${ }^{29,30}$ Our results to support the role of midluteal serum E2 in acquiring pregnancy are in contrast to a study of Ganesh et al in which midluteal serum E2 level was estimated 11 days after OI. ${ }^{30}$ The low peak to mid luteal E2 observed in medium and high FORT groups in the present study emphasizes the role of midluteal E2 for decidualization of endometrium similar to another study. $^{26}$

Progesterone (P), a hormone of secretory phase causes mast cell maturation and release of cytokines and growth factors which are required for uterine receptivity. ${ }^{4,31}$ The role of $\mathrm{P}$ on outcome of ART has remained controversial. The $\mathrm{P}$ level on the day of $\mathrm{hCG}$ administration is considered to be representative of Premature Luteinization (PL) with cut off level from 0.8 to $2 \mathrm{ng}$ $/ \mathrm{ml} .^{32}$ In our study a high $\mathrm{P}$ level above $2 \mathrm{ng} / \mathrm{ml}$ and low E2/P ratio observed in low FORT group associated with decreased implantation and pregnancy in sequence with effect of PL comparable to other studies. ${ }^{4,31,33}$ Cytokines especially IL-I $\beta$ takes part in oocyte development, ovulation, fertilization, thickening of endometrium and preparation of circumstances leading to implantation of embryo. ${ }^{34}$ In this study, females in medium FORT group had high IL-I $\beta$ levels which may represent possible mechanism of successful implantation by increased expression of adhesive protein integrins as documented by others also. ${ }^{35}$

The primary objective of all ART clinics is to achieve maximum implantation potential and minimize chances of multiple pregnancies. $^{36,37}$ The fertilized oocyte undergoes a complex series of events for proper nuclear and cytoplasmic maturation. Gallot et al. has established FORT as a qualitative reflector of ovarian follicle potential and quality of embryos obtained for ICSI treatment cycles as it was observed in our study that high FORT had highest number of fertilized oocytes comparable to other groups. ${ }^{11,18}$ The present study showed that cleaved embryos were significant in high FORT group as compared to low and medium FORT groups as in another study. ${ }^{38}$ This innovative index gives an insight to re-examine the usual criteria of abandonment of cycle just on the basis of number of growing follicles in agreement with Genro et al. ${ }^{18}$
Failure of implantation may occur in any cycle irrespective of transfer of healthy and morphologically normal embryos. Implantation of embryo requires endometrial bed prepared under the influence of hormones and cytokines in the window of implantation. ${ }^{4}$ The measurement of endometrial thickness to allow implantation of fertilized ovum has been documented by a number of researchers. Rinaldi et al. ${ }^{40}$ observed that a peri-ovulatory endometrial thickness of 9 and $10 \mathrm{~mm}$ is associated with $91 \%$ of conception cycles. In a study done by Rehman et al. endometrial thickness of $8 \mathrm{~mm}$ was found to be optimal for implantation which was observed in our study females of high FORT group. ${ }^{41}$ Females of medium FORT group however had endometrial thickness greater than $10 \mathrm{~mm}$.

This study also showed that the number of positive reproductive outcomes is better in high FORT group supported by the data of another study for non PCOS. ${ }^{39}$ This study also showed an interesting finding which is not noticed or highlighted in the earlier studies that the high FORT showed better embryo parameters whereas endometrial thickening was maximum in medium FORT. It is still debatable that this finding has played any role in the positive outcome of the assisted reproduction or not. Moreover study is limited as only non PCOS patients were taken, hyper stimulation cases were not recognized in all FORT groups, different sonographers measured AFC and PFC and study has not compared the index with Anti Mullerian hormone which is a well-known representative of ovarian response. This however is the first study in the region that has emphasized the role of FORT index in the determination of reproductive outcome of ICSI patients. Application of this cost effective index can reduce cancellation rates and may predict better outcome after ICSI. It may help to replace the term poor and good ovarian responders for cancellation of cycles.

\section{CONCLUSION}

The high FORT group had the highest number of retrieved, fertilized and mature oocytes, cleaved embryos, and favorable endometrial lining. Estimation of hormones in high FORT group revealed a high peak and mid luteal $\mathrm{E} 2$, high peak and low mid luteal IL-I $\beta$ and low P levels in both phases of ovarian cycle which was associated with greater number of clinical pregnancies. It can thus be concluded that the index calculated by the ratio of the PFC to the small antral follicle count in non PCOS patients can be used as a predictor of oocyte competence and may reflect reproductive outcome after ICSI.

\section{Funding: No funding sources \\ Conflict of interest: None declared}

Ethical approval: The study was approved by the ethical review board of Islamabad clinic serving infertile couples 


\section{REFERENCES}

1. Rijal B, Shrestha R, Jha B. Association of thyroid dysfunction among infertile women visiting infertility center of Om Hospital, Kathmandu, Nepal. Nepal Med Coll J. 2011;13(4):247-9.

2. Shaheen R, Fazil S, Sultan S, Subhan K, Tahir F. Prevalence of infertility in a cross section of Pakistani population. Pakistan J Zool. 2010;42(4):389-93.

3. Rehman R, Hussain Z, Zuberi NA. Prediction of success in intracytoplasmic sperm injection (ICSI) by estimation of serum estradiol/progesterone ratio on the day of embryo transfer. J Pak Med Assoc. 2013;63(5):609-13.

4. Rehman R, Hussain Z, Siddiq A. Role of progesterone in human embryo implantation. Rawal Med J. 2012;37(2):194-8.

5. Toporcerova S, Adam J, Toporcer T, Hredzak R, Ostro A. Basal concentrations of FSH (follicle stimulating hormone) as a transfer outcome. Hum Reprod. 2006;27(4):1066-72.

6. Arslan M, Bocca S, Mirkin S, Barroso G, Stadtmauer L, Oehninger S. Controlled ovarian hyperstimulation protocols for in vitro fertilization: two decades of experience after the birth of Elizabeth Carr. Fertil Steril. 2005;84:555-69.

7. Rehman R, Hussain Z, Fatima SS. Effect of weight status on pregnancy outcome in intra cytoplasmic sperm injection. Iran J Reprod Med. 2013;11(9):71724.

8. Bancsi LF, Broekmans FJ, Looman CW, Habbema JD, Velde ER. Predicting poor ovarian response in IVF: use of repeat basal FSH measurement. J Reprod Med. 2004;49(3):187-94.

9. Broer SL, Mol BW, Hendriks D, Broekmans FJ. The role of antiMullerian hormone in prediction of outcome after IVF: comparison with the antral follicle count. Fertil Steril. 2009;91:705-14.

10. Melo MA, Garrido N, Alvarez C, Bellver J, Meseguer M, Pellicer A, et al. Antral follicle count (AFC) can be used in the prediction of ovarian response but cannot predict the oocyte/embryo quality or the in vitro fertilization outcome in an egg donation program. Fertil Steril. 2009;91:148-56.

11. Gallot V, Berwanger da Silva AL, Genro V, Grynberg M, Frydman N, Fanchin R. Antral follicle responsiveness to follicle-stimulating hormone administration assessed by the Follicular Output RaTe (FORT) may predict in vitro fertilizationembryo transfer outcome. Hum Reprod. 2012;27(4):1066-72.

12. Gougeon A. Regulation of ovarian follicular development in primates: facts and hypotheses. Endocr Rev. 1996;17(2):121-55.

13. Guerif F, Lemseferr M, Blanchard M, Dominique Royere D. Top quality embryos at day 2: a prerequisite for single blastocyst transfer? An observational cohort study in women under 36 . Assist Reprod Genet. 2009;26:443-9.
14. Kondapalli LA, Molinaro TA, Sammel MD, Dokras A. A decrease in serum estradiol levels after human chorionic gonadotrophin administration predicts significantly lower clinical pregnancy and live birth rates in in vitro fertilization cycles. Hum Reprod. 2012;27:2690-7.

15. Schoevers EJ, Kidson A, Verheijden JHM, Bevers MM. Effect of follicle-stimulating hormone on nuclear and cytoplasmic maturation of sow oocytes in vitro. Theriogenology. 2003;59(9):2017-28.

16. Aktan E, Bozkurt K, Ozer D, Yucebilgen S, Karadadas N, Bilgin O. The effect of mid luteal estradiol level on the outcome of ICSI-ET cycles. Arch Gynecol Obstet. 2004;269(2):134-8.

17. Faddy M. Follicle dynamics during ovarian ageing. Molecul Cellul Endocrinol. 2000;163(1-2):43-8.

18. Genro VK, Grynberg M, Scheffer JB, Roux I, Frydman R, Fanchin R. Serum anti-Mullerian hormone levels are negatively related to follicular output rate (FORT) in normo-cycling women undergoing controlled ovarian hyper stimulation. Hum Reprod. 2011;26:671-7.

19. Asimakopoulos B, Koster F, Felberbaum R, AlHasani S, Diedrich K, Nikolettos N. Cytokine and hormonal profile in blood serum and follicular fluids during ovarian stimulation with the multidose antagonist or the long agonist protocol. Hum Reprod. 2006;21(12):3091-5.

20. Luna M, Grunfeld L, Mukherjee T, Sandler B, Copperman AB. Moderately elevated levels of basal follicle-stimulating hormone in young patients predict low ovarian response, but should not be used to disqualify patients from attempting in vitro fertilization. Ferti Steril. 2007;87(4):782-7.

21. Jurema MW, Bracero NJ, Garcia JE. Fine tuning cycle day 3 hormonal assessment of ovarian reserve improves in vitro fertilization outcome in gonadotropin-releasing hormone antagonist cycles. Fertil Steril. 2003;80(5):1156-61.

22. Phophong P, Ranieri DM, Khadum I, Meo F, Serhal P. Basal 17b-estradiol did not correlate with ovarian response and in vitro fertilization treatment outcome. Fertil Steril. 2000;74:1133-6.

23. Kassab A, Sabatini L, Lieberman G, Tozer A, Zosmer A, Davis C, et al. Does measuring early basal serum follicular luteinizing hormone assist in predicting in vitro fertilization (IVF) / intracytoplasmic sperm injection (ICSI) outcome? Reprod Biol Endocrinol. 2007;5:32.

24. Ottosen LD, Kesmodel U, Hindkjaer J, Ingerslev HJ. Pregnancy prediction models and eSET criteria for IVF patients: do we need more information? J Assist Reprod Genet. 2007;24:29-36.

25. Kara M, Tutlu K, Sofuoglu K, Devranoglu B, Cetinkaya T. Association between serum estradiol level on the hCG administration day and IVF-ICSI outcome. Iran J Reprod Med. 2012;10:53-8.

26. Rehman R, Hussain Z, Zahir H, Khan R. Impact of peak/mid luteal estradiol on pregnancy outcome after 
intracytoplasmic sperm injection. J Pak Med Assoc. 2014;64:780-4.

27. Rehman R, Jawaid S, Gul H, Khan R. Impact of peak estradiol levels on reproductive outcome of intracytoplasmic sperm injection. Pak J Med Sci. 2014;30(5):986-91.

28. Russell DL, Robker RL. Molecular mechanisms of ovulation: coordination through cumulus complex. Hum Reprod Update. 2007;13 289-312.

29. Blazer AS, Hogen JW, Frankfurter D, Hackett R, Keefe DL. Serum estradiol positively predicts outcome in patients undergoing in vitro fertilization. Fertil Steril. 2004;81(6):1707-9.

30. Ganesh A, Goswami S, Chattopadhyay R, Chakraborty C, Chaudhury K, Chakravarty BN. Luteal phase estradiol level: a potential predictive marker for successful pregnancy in in vitro fertilization/intracytoplasmic sperm injection. Fertil Steril. 2009;91:1018-22.

31. Fujimoto A, OsugaY, Fujiwara T, Yano T, Tsutsumi $\mathrm{O}$, Momoeda $\mathrm{M}$, et al. Human chorionic gonadotropin combined with progesterone for luteal support improves pregnancy rate in patients with low late-mid-luteal estradiol levels in IVF Cycles. J Assist Reprod Genet. 2002;19:550-4.

32. Jensen J, Lavy Y, Holzer H, Hurwitz A, Simon A, Revel A, et al. Young low responders protected from untoward effects of reduced ovarian response. Fertil Steril. 1998;69:1001-4.

33. Ou YC, Lan KC, Chang SY, Kung FT, Huang FJ. Increased progesterone/estradiol ratio on the day of HCG administration adversely affects success of in vitro fertilization-embryo transfer in patients stimulated with gonadotrophin-releasing hormone agonist and recombinant follicle-stimulating hormone. Taiwan J Obstet Gynecol. 2008;47:168-74.

34. Stravreus-Evers A, Nikas G, Sahlin L. Formation of pinopodes in human endometrium is associated with the concentrations of progesterone and progesterone receptors. Fertil Steril. 2001;76:782-91.

35. Mendoza C, Cremades N, Ruiz-Requena E, Martinez F, Ortega E, Bernabeu S, et al. Relationship between fertilization results after intracytoplasmic sperm injection, and intrafollicular steroid, pituitary hormone and cytokine concentrations. Hum Reprod. 1999;14(3):628-35.

36. Guzeloglu-Kayisli O, Basar M, Arici A. Basic aspects of implantation. Reprod Biomed Online. 2007;15(6):728-39.

37. Hanoch J, Lavy Y, Holzer H, Hurwitz A, Simon A, Revel A, et al. Young low responders protected from untoward effects of reduced ovarian response. Fertil Steril. 1998;69:1001-4.

38. Rehman R, Hussain Z, Faraz N. Effect of estradiol levels on pregnancy outcome in obese females. J Ayub Med Coll Abbottabad. 2012;24(3):3-5.

39. Zhang N, Hao CF, Zhuang LL, Liu XY, Gu HF, Liu $\mathrm{S}$, et al. Prediction of IVF/ICSI outcome based on the follicular output rate (FORT). Reprod Bio Med Online. 2013;27(2):147-53.

40. Rinaldi L, Lisi F, Floccari A, Lisi R, Pepe G, Fishel $\mathrm{S}$. Endometrial thickness as a predictor of pregnancy after in-vitro fertilization but not after intracytoplasmic sperm injection. Hum Reprod. 1996;11(7):1538-41.

41. Rehman R, Jawaid S, Hussain M, Katpar S, Baig M. Role of hormones and cytokines in creating an attractive endometrial bed for fertility: a quasi-study. Int J Recent Sci Res. 2014;5(7):1357-60.

DOI: $10.5455 / 2320-1770$. ijrcog20150224

Cite this article as: Rehman R, Mustafa R, Hoor T, Khan R, Gul H. Importance of estimation of follicular output rate (FORT) in females assisted by intracytoplasmic sperm injection. Int $\mathrm{J}$ Reprod Contracept Obstet Gynecol 2015;4:131-9. 